\title{
A Preliminary Study on Bioremediation of Zinc, Copper and Lead using Rumen Fluid
}

\author{
S. Meignanalakshmi*, M. Charulatha and K. Vijayarani \\ Department of Animal Biotechnology, Madras Veterinary College, \\ TANUVAS, Chennai-7, India \\ *Corresponding author
}

A B S T R A C T

\section{Keywords}

Bioremediation, Heavy metals,

Rumen fluid,

Slaughter house

\section{Article Info}

Accepted:

17 January 2018

Available Online:

10 February 2018
Rumen fluid a major slaughter house waste is known to have numerous microorganisms which include bacteria, fungi, protozoa, Archaea and viruses. These Microbes in the rumen fluid not only have the ability to ferment a variety of carbohydrates but also degrades and ferment a significant portion of dietary protein. In the present study the rumen fluid is evaluated for its ability to reduce heavy metals- Zinc, Copper and Lead. Rumen fluid collected from slaughter house was inoculated in Nutrient broth added with heavy metalsZinc, Copper and Lead. The medium was collected for every $24 \mathrm{hrs}$ and was centrifuged and the supernatant was analyzed for the heavy metal reduction. The Bioremediation of heavy metals- Zinc, Copper and Lead was evaluated for 96hours and was found to be reduced in the medium at $96^{\text {th }} \mathrm{hr}$ by $40 \%, 33 \%$ and $15 \%$ respectively.

\section{Introduction}

Heavy metals are essential trace elements, but most of them can be toxic to all forms of life at high concentrations due to formation of complex compounds within the cell. Unlike other organic pollutants, heavy metals once introduced into the environment cannot be biodegraded causing pollution of air, water, and soils. Heavy metals enter plant, animal and human tissues via air inhalation, food chain and manual handling. These Heavy metals once entered can bind to vital cellular components, such as structural proteins, enzymes, and nucleic acids, and interfere with their functioning. The long-term exposure to heavy metals can have carcinogenic, central and peripheral nervous system and circulatory effects in humans. Thus, the bioavailability, mobility, and toxicity of metals in the environment should be reduced. Commonly used methods of remediating heavy metalcontaminated environments are in situ vitrification and soil incineration and land filling, soil washing, soil flushing and solidification and stabilization by electrokinetic systems. These physicochemical methods of remediation are expensive and environmentally destructive. Thus bioremediation- an environmentally friendly approach is used as an alternative to physicochemical methods of remediation 
(Madhu Choudary et al., 2017). Bioremediation is the process of utilizing microbes such as bacteria, yeast, fungi, algae and higher plants as main tools in treating oil spills and heavy metals existing in the environment (Gupta et al, 2016). Due to natural and industrial processes heavy metals are found increasingly in microbial habitats. Thus, microorganisms have evolved several mechanisms to tolerate the heavy metal presence by adsorption, complexation, or chemical reduction of metal ions or to use them as terminal electron acceptors during anaerobic respiration (Mohammed et al., 2011). The rumen fluid comprises of obligately anaerobic bacteria, fungi and protozoa (Forsberg and Cheng, 1992). Bacillus sp. commonly present in rumen fluid has been known in uptake of Copper and Zinc by $15 \%$ and $14 \%$ dry weight (Rajendran et al., 2003). Rumen consortia have been used for chromium reduction by biosorption (Meignanalaksmi et al., 2013). In the present study microbial consortia in the rumen fluid is evaluated for its ability to bioremediate the three commonly polluting heavy metals Zinc, Lead and Copper.

\section{Materials and Methods}

\section{Collection of Rumen fluid- Slaughter house waste}

Rumen fluid was collected from Perambur slaughter house.

\section{Analysis of heavy metal reduction}

Rumen fluid of about $1 \mathrm{ml}$ was inoculated to $100 \mathrm{ml}$ of nutrient broth added with heavy metals Zinc, Copper and lead (2ppm, 6.5ppm and 210ppm) in separate flasks (Sujitha and Jayanthi, 2014). The medium was incubated in shaking condition at $37^{\circ} \mathrm{C}$ for 4 days. All the experiments were carried out in triplicates. The medium was collected at regular intervals- $0^{\text {th }}, 24^{\text {th }}, 48^{\text {th }}, 72^{\text {nd }}$ and $96^{\text {th }}$ hours respectively. The collected medium was centrifuged at 6000rpm for $10 \mathrm{~min}$ and the supernatant was collected. The supernatant was estimated for the heavy metals- Zinc (Tazul Islam and Jammaludin Ahmed, 2013), Copper (Vadiraj and Belagali, 2014) and lead (Humaria Khan et al., 2006).

\section{Results and Discussion}

The heavy metals inoculated with rumen fluid were evaluated for its ability to bioremediate heavy metals and the heavy metal reduction studies are given in table 1. The percent reduction of heavy metals- Zinc, Copper and Lead was calculated and are given in table 2 . The graphical representation of heavy metal reduction is shown in figure 1 and 2 .

In the present study heavy metals Zinc, Copper and Lead was found to be reduced by $40 \%, 33 \%$ and $15 \%$ when rumen fluid was used. Kang et al., 2016 showed remediation of $\mathrm{Pb}$ by $98.3 \%, \mathrm{Cd}$ by $85.4 \%$ and $\mathrm{Cu}$ by $5.6 \%$ using cocultures of Viridibacillus arenosi B-21, Sporosarcina soli B-22, Enterobacter cloacae KJ-46, and E. cloacae $\mathrm{KJ}-47$, which are isolated from an abandoned mine site. Saccharomyces cerevisiae was used by Dilna Damodaran et al., (2011) and reported the reduction of lead by $67-82 \%$ and Cadmium by $73-79 \%$ in 30 days.

Maximum heavy metal adsorption by the immobilized bacterial cell Bacillus Subtilis $\left(78.4 \mathrm{mg} / \mathrm{L}\right.$ for $\mathrm{Zn}^{2+}, 76.8 \mathrm{mg} / \mathrm{L}$ for $\mathrm{Cu}^{2+}$ and $74.2 \mathrm{mg} / \mathrm{L}$ for $\mathrm{Pb}^{2+}$ ) has been shown by Sujitha and Jayanthi (2014). Immobilized Serratia marcescens showed maximum absorption of Zinc (74.8 mg/L), Copper (72.3 $\mathrm{mg} / \mathrm{L}$ ) and Lead (71.4 $\mathrm{mg} / \mathrm{L}$ ) (Sujitha and Jayanthi, 2014). Pseudomonas fluorescens was immobilized by Sujitha and Jayanthi (2014) and reported maximum absorption $\left(70.3 \mathrm{mg} / \mathrm{L}\right.$ for $\mathrm{Zn}^{2+}, 69.8 \mathrm{mg} / \mathrm{L}$ for $\mathrm{Cu}^{2+}$ and $68.4 \mathrm{mg} / \mathrm{L}$ for $\mathrm{Pb}^{2+}$ ). 
Table.1 Zinc, copper and lead reduction by rumen fluid for every $24 \mathrm{hrs}$

\begin{tabular}{|l|l|l|l|}
\hline Time in hours & Zinc (ppm) & Copper (ppm) & Lead (ppm) \\
\hline \multicolumn{4}{|c|}{ Mean \pm S.D. } \\
\hline 0 (Initial value) & $2.00 \pm 0.01$ & $6.5 \pm 0.01$ & $210 \pm 1.00$ \\
\hline $\mathbf{2 4}$ & $1.84 \pm 0.01$ & $6.36 \pm 0.01$ & $208 \pm 1.00$ \\
\hline $\mathbf{4 8}$ & $1.2 \pm 0.1$ & $4.36 \pm 0.01$ & $178 \pm 1.00$ \\
\hline $\mathbf{7 2}$ & $1.2 \pm 0.1$ & $4.36 \pm 0.01$ & $178 \pm 1.00$ \\
\hline $\mathbf{9 6}$ & $1.2 \pm 0.1$ & $4.36 \pm 0.01$ & $178 \pm 1.00$ \\
\hline
\end{tabular}

Table.2 Percent reduction of heavy metals by rumen fluid

\begin{tabular}{|l|l|}
\hline Heavy metal & $\begin{array}{l}\text { Percent reduction at the end of } \mathbf{9 6}^{\text {th }} \\
\text { hour }\end{array}$ \\
\hline Zinc & $40 \%$ \\
\hline Lead & $15 \%$ \\
\hline Copper & $33 \%$ \\
\hline
\end{tabular}

Fig.1 Reduction of zinc and copper by rumen fluid at every $24 \mathrm{hrs}$

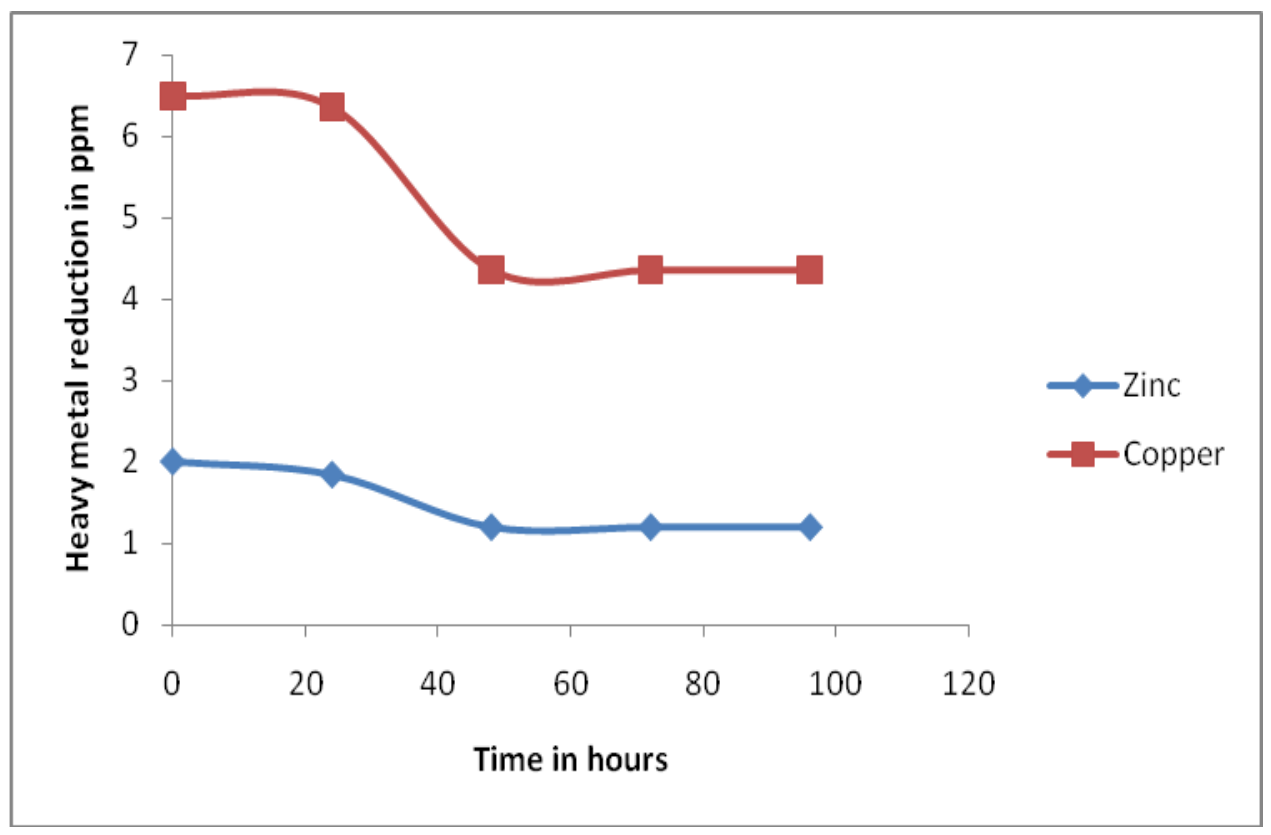


Fig.2 Reduction of lead by rumen fluid at every $24 \mathrm{hrs}$

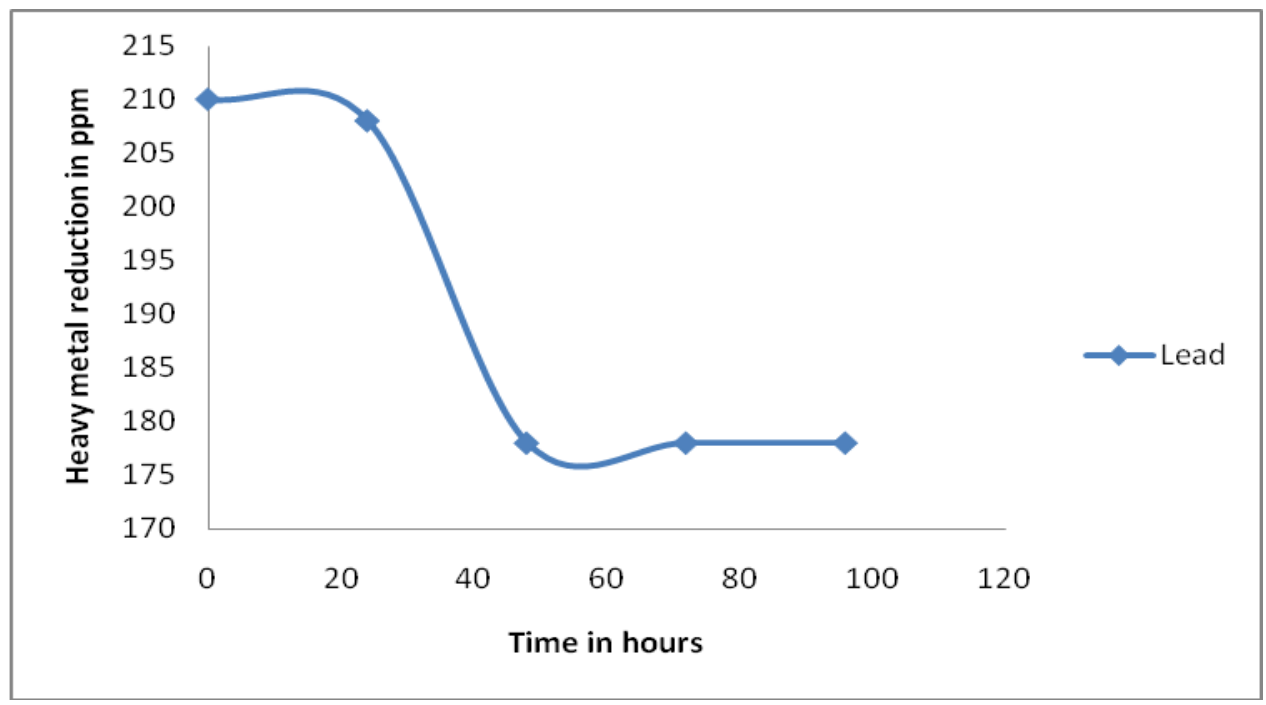

Krishna et al, 2013 used Bacillus sp to reduce Zinc to the maximum of about $40 \%$. Reduction of copper levels in soil added with bacteria when compared to raw soil sample was shown by Bini Samal and Parul Bhatt Kotiyal (2013). Arun Karnwal and Vaishali Bhardwaj (2014) isolated bacterial strain vb4 from metal contaminated areas in and around Baddi and was found to be the potent producer of biosurfactant as well as found to efficiently remove zinc and chromium.

Sayed et al., (2011) showed maximum uptake of Zinc by using Streptomyces aureofacienes (734.8 Zinc $\mu \mathrm{g} / \mathrm{g}$ of biomass). Arpita Ghosha and Papita Das Saha (2012) isolated Copper resistant bacteria Stenotrophomonas sp. PD2 from soil of Dhapa and had shown maximum copper resistance upto $200 \mathrm{mg} / \mathrm{l}$ of $\mathrm{Cu}$ (II). Biosorption of Chromium by rumen fluid microbes was reported by Meignanalakshmi et al., (2013).

In the present study rumen fluid containing millions of microbes was used for Bioremediation of copper, zinc and lead when compared to other studies where individual microbes have been used. As rumen fluid contains diverse of microbes it could able to reduce all the three heavy metals.

Hence, concluded in the present study rumen fluid a major slaughter house waste has been proved to bioremediate heavy metals- Zinc, Copper and Lead and can be used in future as a method of low cost and ecofriendly remediation technique.

\section{Acknowledgment}

The authors express their gratitude to The State planning commission - Tamil Nadu state land use research board (SPCTNSLURB) for financially supporting this research project.

\section{References}

Arpita Ghosh and Papita Das Sahe. 2012. Bioremediation of Copper present in waste water using isolated Microorganism Stenotrophomonas sp. PD2 from Soil of Dhapa, Kolkata, India. Elixir Pollution. 47:8921-8923.

Arun Karnwal and Vaishali Bhardwaj. 2014. Bioremediation of heavy metals ( $\mathrm{Zn}$ and 
Cr) using microbial biosurfactant. Journal of Environmental Research and Protection Journal of Environmental Research and Protection. 11(1): 29-33.

Bini Samala and B. Parul Bhatt Kotiyal. 2013. Bioremediation of Copper Contaminated Soil Using Bacteria. Octa Journal of Environmental Research. 1(1): 5-8.

Dilna Damodaran, Gummadi Suresh and B. Raj Mohan. 2011. Bioremediation of Soil by Removing Heavy Metals Using Saccharomyces cerevisiae. $2^{\text {nd }}$ International Conference on Environmental Science and Technology. 6.

Forsberg, C. W. and K. J. Cheng. 1992. Molecular strategies to optimize forage and cereal digestion by ruminants. In: Biotechnology and Nutrition (Ed. D. D. Bills and S.-D. Kung). Butterworth Heinmann, Stoneham, UK.107-147.

Gupta, A., J. Joia, A. Sood, R. Sood, C. Sidhu and G. Kaur. 2016. Microbes as Potential Tool for Remediation of Heavy Metals: A Review. J Microb Biochem Technol. 8:364-372.

Humaria Khan, M. Jamaluddin Ahmed, and M. Iqbal Bhanger. 2006. A simple spectrophotometric method for the determination of trace level lead in biological samples in the presence of aqueous micellar solutions. Spectroscopy. 20(2006): 285-297.

Kang, C.H., Y.J. Kwon and J.S. So. 2016. Bioremediation of heavy metals by using bacterial mixtures. Ecological Engineering. 89:64-69.

Krishna, M.P., Rinoy Varghese, V. Arun Babu, S. Jyothy, and A. A. Mohamed Hatha. 2013. Bioremediation of Zinc using Bacillus sp. isolated from metal contaminated industrial zone. Prospects in Bioscience: Addressing the Issues. Pp. 1118.

Madhu Choudhary,

Raman Kumar,
Ashim Datta, Vibha Nehra and Neelam Garg. 2017. Bioremediation of heavy metals by microbes. Bioremediation of Salt Affected Soils: An Indian Perspective. Pp. 233-255.

Meignanlakshmi, S., J. Deepika and S. Vinoth Kumar. 2013. A Preliminary Study on Biosorption of Chromium by Rumen Consortia. International Journal of Scientific Research. 2(6): 281-282.

Mohammed, A.S, A. Kapri and R. Goel. 2011. Heavy Metal Pollution: Source, Impact, and Remedies. Biomanagement of MetalContaminated Soils. Pp. 1-28.

Rajendran, P., J. Muthukrishnan and P. Gunasekaran. 2003. Microbes in heavy metal remediation. Indian Journal of Experimental Biology. 41: 935-944.

Sayed, O.H.E.I., H.M. Refaat, M.A. Swellam, M.M. Amer, A.I. Attwa and M.E.E.I. Awady. 2011. Bioremediation of Zinc by Streptomyces aureofacienes. Journal of Applied Sciences. 11(5): 873-877.

Sujitha, D. and M. Jayanthi. 2014. Efficiency of immobilized microbial combination for the bioremediation of tannery effluents in Vellore District, Tamil Nadu, India. International Journal of Advanced Research in Biological Sciences. 1(8): 113-120.

Tazul Islam, M. and M. Jamaluddin Ahmed. 2013. A Simple Spectrophotometric Method for the Trace Determination of Zinc in Some Real, Environmental, Biological, Pharmaceutical, Milk and Soil Samples Using 5,7- Dibromo-8hydroxyquinoline. Pak. J. Anal. Environ. Chem. 14(1): $01-15$.

Vadiraj, K.T. and S.L. Belagali. 2014. Spectrophotometric determination of copper (II) in industrial effluent samples using sulfanilic acid as a ligand system. Bulgarian Chemical Communications. 46(3): $447-451$.

\section{How to cite this article:}

Meignanalakshmi, S., M. Charulatha and Vijayarani, K. 2018. A Preliminary Study on Bioremediation of Zinc, Copper and Lead using Rumen Fluid. Int.J.Curr.Microbiol.App.Sci. 7(02): 2041-2045. doi: https://doi.org/10.20546/ijcmas.2018.702.244 